Technical Note

\title{
Textural-Spectral Feature-Based Species Classification of Mangroves in Mai Po Nature Reserve from Worldview-3 Imagery
}

\author{
Ting Wang ${ }^{1,2}$, Hongsheng Zhang ${ }^{1,2}$, Hui Lin ${ }^{1,2,3,4}$ and Chaoyang Fang ${ }^{3, *}$ \\ Received: 28 August 2015; Accepted: 25 December 2015; Published: 31 December 2015 \\ Academic Editors: Chandra Giri, Parth Sarathi Roy and Prasad S. Thenkabail \\ 1 Institute of Space and Earth Information Science, The Chinese University of Hong Kong, New Territories, \\ Hong Kong, China; wangtingwhu@126.com (T.W.); stevenzhang@cuhk.edu.hk (H.Z.); \\ huilin@cuhk.edu.hk (H.L.) \\ 2 Shenzhen Research Institute, The Chinese University of Hong Kong, Shenzhen 518057, China \\ 3 Key Laboratory of Poyang Lake Wetland and Watershed Research, Ministry of Education, \\ Jiangxi Normal University, Nanchang 330022, China \\ 4 Department of Geography and Resource Management, The Chinese University of Hong Kong, \\ New Territories, Hong Kong, China \\ * Correspondence: fcy@jxnu.edu.cn; Tel.: +86-0791-88120539; Fax: +86-0791-88120537
}

\begin{abstract}
The identification of species within an ecosystem plays a key role in formulating an inventory for use in the development of conservation management plans. The classification of mangrove species typically involves intensive field surveys, whereas remote sensing techniques represent a cost-efficient means of mapping and monitoring mangrove forests at large scales. However, the coarse spectral resolution of remote sensing technology has up until recently restricted the ability to identify individual species. The more recent development of very high-resolution spatial optical remote sensing sensors and techniques has thus provided new opportunities for the accurate mapping of species within mangrove forests over large areas. When dealing with the complex problems associated with discriminating among species, classifier performance could be enhanced through the adoption of more intrinsic features; such as textural and differential spectral features. This study explored the effectiveness of textural and differential spectral features in mapping mangrove inter-species obtained from WorldView-3 high-spatial-resolution imagery for mangrove species in Hong Kong. Due to the different arrangement of leaves, the branch density, and the average height and size of plants, we found that the differential spectral features could aid in reducing inner-species variability and increasing intra-species separation. Using a combination of textural and differential spectral features thus represents a promising tool for discriminating among mangrove species. Experimental results suggest that combining these features can greatly improve mapping accuracy, thereby providing more reliable mapping results.
\end{abstract}

Keywords: mangrove; inter-species; textural; spectral; high-resolution

\section{Introduction}

Mangroves are salt-tolerant evergreen forests that grow in the intertidal zones of marine, coastal and estuarine ecosystems of tropical and subtropical areas [1]. Mangrove forests are irreplaceable habitats that sustain unique biodiversity and provide crucial ecosystem services to humans [2], yet despite their socio-economic value to coastal communities they are among the most highly threatened habitats globally [3]. As of 2000, mangrove forests covered an area of approximately $137,760 \mathrm{~km}^{2}$ in 118 countries and territories [4], with the largest extent located in Asia. One of the most representative 
areas in Asia is the Mai Po Nature Reserve in the New Territories, which comprises the largest protected zone for mangroves in Hong Kong. As mangrove forests are extremely sensitive to changes in climate, water pollution and other environmental factors, analysis of their distribution and species composition has become an area of great interest to both researchers and governments [5-9].

Given their geographic locations and physical structure, mangrove forests are often very difficult to access for the purpose of extensive field sampling; as a consequence, remote sensing is often used for mapping, classifying, assessing, and determining species composition of mangrove forests $[4,10]$. In recent years, numerous studies employing remote sensing methods have been undertaken to discover the economic and ecological values of mangrove ecosystems and to provide data useful for effective forest management [11,12]. Multispectral sensors on satellite platforms, including synthetic aperture radar (SAR), Landsat TM, and SPOT XS, are most commonly used in studies of mangrove forests due to their cost-effectiveness and large-scale coverage [13], but such approaches are often inadequate for fine-scale species recognition. However, the commercial availability of high-spatial-resolution satellite imagery has created new opportunities for mapping mangrove forests at local scales [14]. IKONOS and QuickBird satellite imagery have been combined with different image processing techniques to distinguish three mangrove species on the Caribbean coast of Panama, for instance [15], and QuickBird imagery was used to map black mangrove forests along the Gulf Coast of Texas to the species level [16]. Further application of high-spatial-resolution aerial photography or satellite imaging would also provide for more detailed and accurate mapping of wetland areas [5].

Reliance on coarse-spectral-resolution imagery limited the number of species that could be distinguished. Heumann [17] further demonstrated that mapping mangrove species composition using high-spatial-resolution data presents further challenges: (i) the accurate demarcation of the precise community boundaries of mangrove forests is extremely difficult, due to the seasonal, tidal and spectral variability of the communities [13,14,18]; (ii) spectral reflectance values of mangrove vegetation are often difficult to separate from those of underlying mudflat and water [7]; and (iii) the spectral differences among species of mangroves are subtle [19,20]. As a result, the difficulty in differentiating between mangrove species and differentiating mangroves from other types of vegetation and mudflats reduces classification accuracy [6,19]. Using the Mai Po Nature Reserve as an example, more than six perennial mangrove species have been reported [21,22]. It is difficult to obtain accurate classification results directly from high-spatial-resolution images with only several bands.

Grey-Level Co-Occurrence Matrix (GLCM) based features are widely used in image texture analyses, particularly for stochastic texture [23]. Due to the similar spectral responses between different mangrove species, and between mangroves and other types of vegetation, it is necessary to integrate spectral and textural information for more accurate mapping results [24]. As different species of mangroves display distinctive texture patterns, classification based on textural features could fit the demands for mangrove inter-species recognition. From field surveys we found that leaf arrangement, branch density, and average height and size differ among species; these distinctive textures should be identifiable in the image, for instance as "bushy" for Kandelia obovata or "smooth" for Acanthus ilicifoliu. When the spectral features of these two species are similar, two forms of Acanthus ilicifoliu with different leaf shape will show discrepancies in textural features, which are helpful when trying to discriminate between them.

Derivation of the slope of spectral curves is known as derivative spectroscopy [25]. Differential of a spectrum curve or its mathematical function estimates the slope over the entire interval [26]. These methods were originally developed in analytical chemistry to eliminate background signals and resolve overlapping spectral features, but the concepts could be applied to differentiate spectra from remote-sensing imagery, as it can be used to highlight desired information while suppressing or eliminating information of no interest. For example, background absorption or reflectance signals caused by stray light can be eliminated [27]. Spectral curves with sharp structures could also be enhanced [28]. Derivative spectra are sometimes more informative than zero-order reflectance spectra when attempting to glean certain information or relationships from the data; for example, first-order 
derivative spectra in the visible wavelengths has been shown to be more highly correlated with percent leaf surface area infected by a certain type of fungus than the original zero-order reflectance data [26].

The goal of this study was to investigate the value of a WorldView-3 image in mapping different mangrove species, using both spectral and textural features. To make comparisons, three types of features were tested to evaluate their relative effectiveness. More specifically, this study intended to achieve the following three objectives:

(1) To evaluate the use of the eight original bands of WorldView-3 imagery for mapping mangrove species;

(2) To evaluate the use of a combination of the original bands and textural features for mapping mangrove species; and

(3) To evaluate the use of a combination of the original bands, textural features and differential spectral features for mapping mangrove species.

The remainder of the paper is organized as follows: Section 2 illustrates the study area and data; Section 3 briefly reviews the textural and differential spectral features that were used; Section 4 reports the experimental results that were obtained; and finally, a discussion of the results is provided, along with concluding remarks.

\section{Study Area and Data}

The Mai Po Marshes Nature Reserve is located in the northwestern New Territories of Hong Kong and borders the Shenzhen Special Economic Zone of Guangdong Province, China [29] (Figure 1). The geographic coordinates of the reserve are roughly $113^{\circ} 59^{\prime} \mathrm{E}-114^{\circ} 03^{\prime} \mathrm{E}$ and $22^{\circ} 28^{\prime} \mathrm{N}-22^{\circ} 32^{\prime} \mathrm{N}$, bordering the mudflats and mangrove forests of Inner Deep Bay. This area is influenced by the Pearl River and, specifically, by the Shen Zhen River and Deep Bay. The climate of the region is largely governed by the continent of mainland China [8]. The entirety of the Mai Po marshes complex encompasses dwarf mangroves, shrimp ponds and fish ponds, and supports numerous species of wildlife. The Mai Po reserve provides significant habitat for migratory birds and for this reason is considered to be a wetland of international importance under the 1995 Ramsar Convention, a designation that confers some protection for the wide range of natural and man-made habitats in the reserve, especially with regard to the mangrove forests [30].

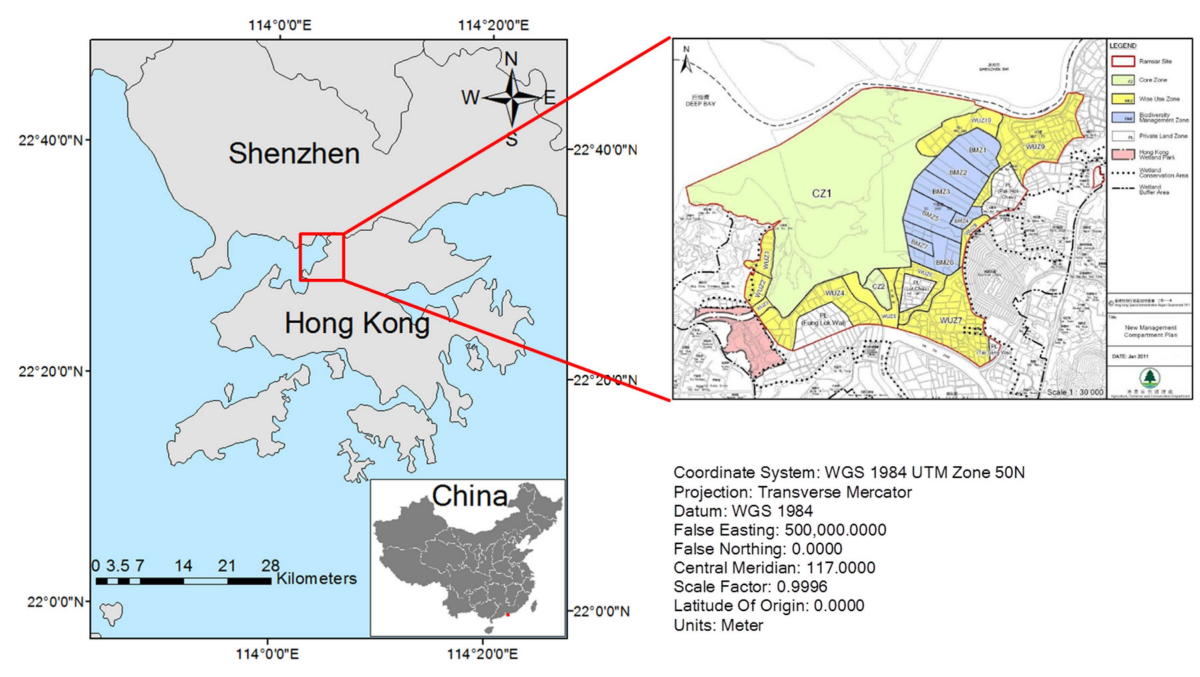

Figure 1. The location of the study area.

The mangroves that ring Inner Deep Bay are the most prominent feature of the reserve. These mangroves are the largest remaining mangrove forest in Hong Kong and one of the few extensive 
mangrove forests left in southern China. To improve management, the reserve has been divided into five separate administrative zones based on habitat type, ecological values and existing land uses by the Agriculture, Fisheries and Conservation Department (AFCD) of Hong Kong. These zones consist of the core zone, the biodiversity management zone, the wise-use zone, the public-access zone, and the private-land zone. The core area of mangrove forest in Inner Deep Bay is approximately $3000 \mathrm{~m}$ long and $500 \mathrm{~m}$ wide and is intersected by several water channels. Mai Po was first declared a nature conservation area in 1975, and designated as a Site of Special Scientific Interest (SSSI) the following year; it was named a nature reserve in 1984 and is presently under the management of the World Wide Fund for Nature (WWF). The ecological significance of the Mai Po reserve is also reflected in the designation of its associated wetland areas as a Wetland of International Importance under the Ramsar Convention. Such international recognition of the site's ecological significance is mainly due to the large number of endemic bird species, many of which are rare species. Despite this, little research has been conducted in this area, primarily because the reserve is restricted to a small area at specific locations, and because of its limited accessibility and its politically sensitive location bordering China.

Eight species of mangrove are found in the Mai Po reserve [31], four of which are dominant native species, according to field studies and a report published by the Agriculture, Fisheries and Conservation Department of Hong Kong. These four spceis are Kandelia obovata and Avicennia marina, which reach the canopy stratum; and Aegiceras corniculatum and Acanthus ilicifolius, which occupy the understory and usually grow along coastal edges. Two other native species, Bruguiera gymnorrhiza and Excoecaria agallocha, are less common, and two exotic tropical species-Sonneratia apetala and Sonneratia caseolaris - were propagated from a plantation located along the Shenzhen River in the Futian National Nature Reserve, in Shenzhen city [21]. According to a previous study [8], four main species of mangroves have been of primary focus, namely Avicennia marina, Acanthus ilicifolius, Kandelia obovata, and Aegiceras corniculatum. Photographs of these four species taken during different phenological periods are shown in Figure 2.

Field studies were conducted in July 2013. A differential GPS (Global Positioning System) was used to match the geographical location between field survey data and image pixel data. Conducting fieldwork in summer is more effective for identifying species because of the presence of flowers. The flowering phase of mangrove forests in Hong Kong is relatively long due to the humid subtropical climate, with some species continuing to blossom as late as November; the spectral features of mangrove leaves are not affected by the presence of these small flowers. According to reserve staff, the distribution of the mangrove species of interest was unchanged between July 2013 and present. Acanthus ilicifolius and Kandelia obovata can both be further separated into two spectral classes, based on differences in their locations and leaf shapes [22]. From field studies it is known that (i) there are two types of Acanthus ilicifolius, one of which has leaves with serrated edges whereas the other has rounded leaves; and (ii) Kandelia obovata is divided into two distinct populations growing on the landward and seaward sides that differ in height and leaf density. Previous studies have divided each of these species into two subclasses [8,21], a classification criterion we follow here.

Launched on the 13th of August 2014, WorldView-3 is a fourth-generation high-spatial-resolution optical satellite operated by the American company DigitalGlobe. With an image-resolution capability $31 \mathrm{~cm}$, WorldView-3 is the highest spatial resolution optical satellite available for civilian use. It can also provide 8-band multispectral imagery with $1.24 \mathrm{~m}$ resolution and 8-band shortwave infrared imagery with $3.7 \mathrm{~m}$ resolution. Because of this range of spectral coverage and near infrared and shortwave infrared capabilities, WorldView-3 images are used for a variety of purposes, including monitoring of vegetation, mineral exploration, coastal monitoring, and other broad applications [9]. Images of the Mai Po Nature Reserve were acquired in January 2015, and cover the entirety of the reserve, with the eight multispectral bands ranging from 400 to $1040 \mathrm{~nm}$.

For this study, we focused solely on the core zone, which is dominated by large extents of mangrove forests; a true-colour image of the core zone is presented in Figure 3. The rectangular data 
cover 59.24 ha; after carefully drawing the border of this area, the core-zone image covers 26.59 ha that remain to be classified.
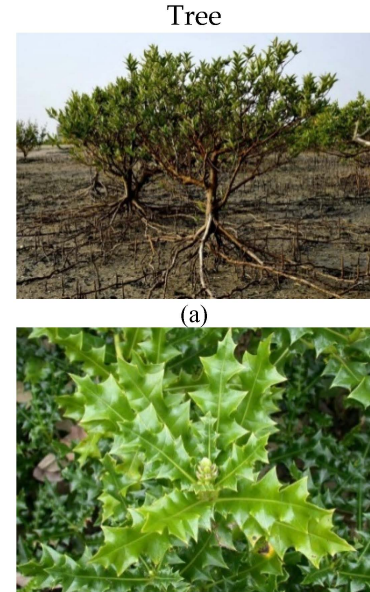

(d)

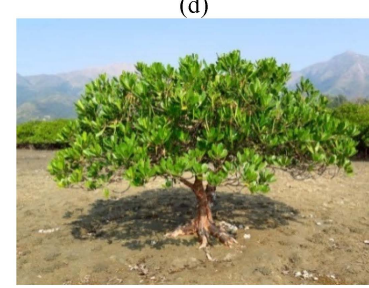

(g)

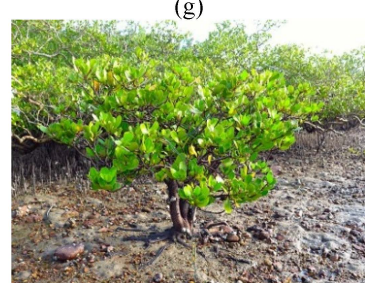

(j)

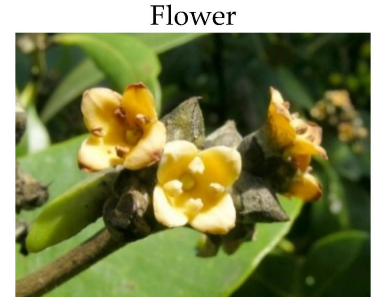

(b)

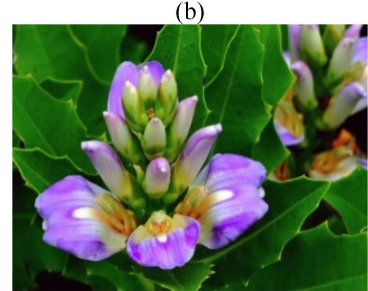

(e)
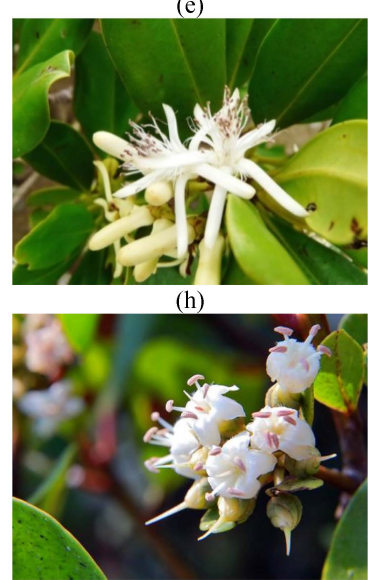

(k)

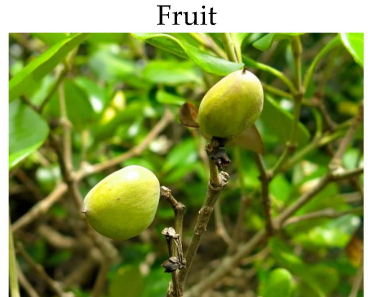

(c)

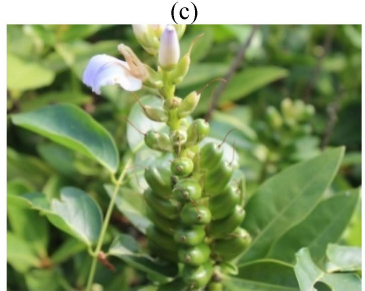

(f)
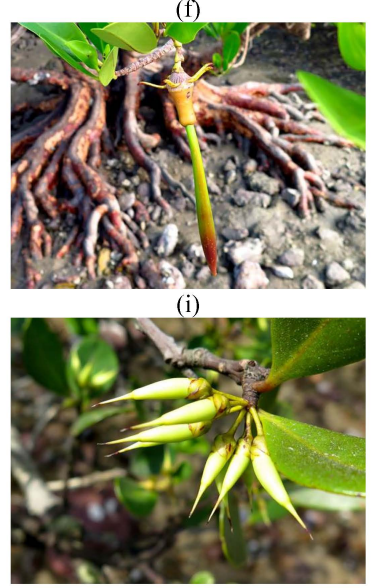

(1)

Figure 2. The four primary species of mangroves in Hong Kong during different phenological periods. (a-c) Avicennia marina; (d-f) Acanthus ilicifolius; (g-i) Kandelia obovata; (j-1) Aegiceras corniculatum.

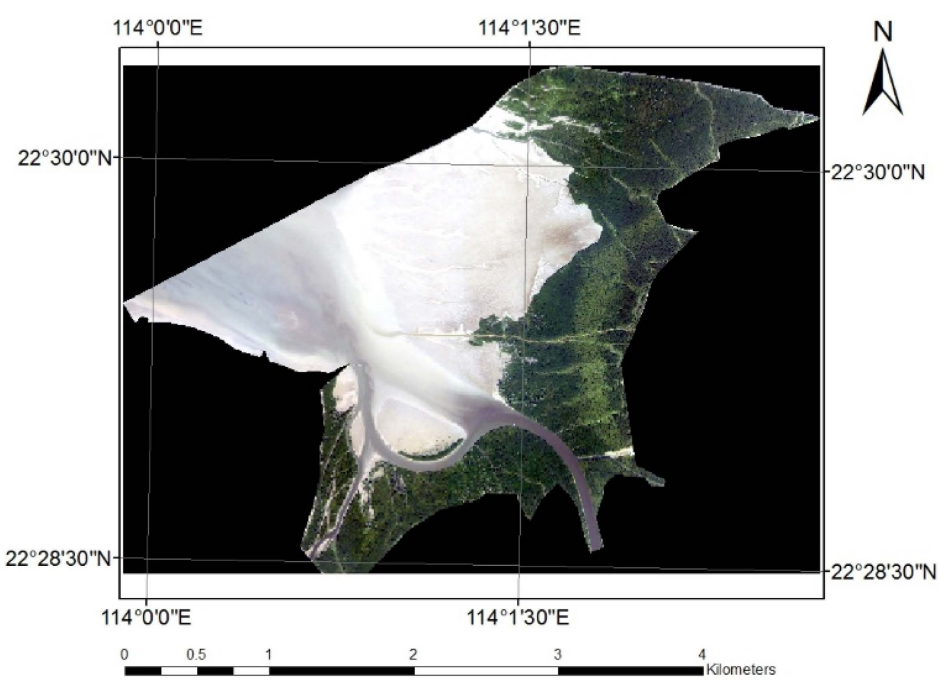

Figure 3. A true-colour image of the core zone. 


\section{Methods}

Several categories of features were adopted for input of the classifier, i.e., the Support Vector Machine (SVM), including the original spectral features, textural features and differential spectral features from the multi-channel data.

\subsection{Preprocessing}

Before the extraction of textural features and differential spectral features, a series of pre-processing steps had been conducted:

(1) Following atmospheric, geometric and radiometric calibration, the spatial resolution of the images was resampled to 1.6 metres when the image was provided by the DigitalGlobe agency.

(2) The region of the core zone of mangrove forests was carefully depicted by ROI tools and the corresponding data were obtained.

(3) Before textural features were calculated, a principal components analysis (PCA) was applied to the original image to extract the first two components from the data; as such, eight textural features were in fact calculated.

(4) The reference data were believed to be representative of the distribution of these six mangrove classes out of four species, supported by the in situ field studies conducted in July 2013. All sample points were divided into two sets based on their spatial distribution, with one set designated for training the classifier and the other for assessing classification accuracy. Samples chosen for training covered all regions, to ensure the completeness of sample characteristics and an unbiased estimation of a certain class of limited extent. The number of reference data collected in the field for each class is shown in Table 1.

Table 1. Sample points for training and accuracy assessment.

\begin{tabular}{cccc}
\hline Classes & Training Samples & Testing Samples & All Samples \\
\hline Avicennia marina & 62 & 62 & 124 \\
Acanthus ilicifolius Group 1 & 40 & 41 & 81 \\
Acanthus ilicifolius Group 2 & 42 & 42 & 84 \\
Kandelia obovata Group 1 & 53 & 54 & 107 \\
Kandelia obovata Group 2 & 51 & 51 & 102 \\
Aegiceras corniculatum & 41 & 41 & 82 \\
Mudflat & 90 & 90 & 180 \\
Waterbody & 74 & 74 & 148 \\
\hline
\end{tabular}

\subsection{Textural Features Extraction}

The features extracted from GLCM have been shown to be powerful tools for image texture analysis [32]. These features compute the statistical characteristic of a certain pixel, based on grey level intensities of the image, and describe how often a pixel of grey level $i$ appears in a specific spatial relationship to the occurrence of pixels of grey level $j$ [33]. In this manner, GLCM defines a square matrix the size of which is equal to the largest grey level $N_{g}$ that appears in the image. The element $\operatorname{GLCM}(i, j)$ located in the $(i, j)$ position of the matrix represents the probability of co-occurrence for pixels with grey levels $i$ and $j$, and an inter-pixel distance $\delta$ and orientation. Although GLCM can to an extent reflect some information regarding distance, orientation, and changes in the magnitude of grey levels, it cannot be directly used as a quantitative index of texture characteristics. Instead, the second-order movements based on GLCM, which have been recognized as textural features, can be applied to various needs of image processing. Haralick et al. [34] proposed 14 original statistics that can be applied to the co-occurrence matrix in order to measure texture features.

The second-order statistical textural features, which include homogeneity, contrast, entropy and correlation, are determined from GLCM images by applying their respective equations (see Table 2). 
(1) Homogeneity. The spatial distribution of grey levels in the image is inferred by homogeneity, where a homogeneously textured image is comprised of a limited range of grey levels, and thus the GLCM image displays few values with relatively high probability, which reflects the changing magnitude of the grey levels in local areas in the image. Where the digital number values for a specific region are similar, homogeneity tends to be large.

(2) Contrast. While the contrast in intensity between a pixel and its neighbour is determined over an entire image. It is strongly related to the clarity of the image and it has been shown that pixels with similar values results in low contrast, making boundary demarcations between features of interest more difficult.

(3) Entropy. Textural uniformity is calculated using the equation shown in Table 1 and expressed statistically as measured energy. This suggests that the maximum constant values or periodic uniformity in grey level distribution will attain maximum energy if there is complex texture in the image. Clear domain of group of textures in deciphered on account of higher value in energy measure.

(4) Correlation. Correlation refers to how closely related a reference pixel is to its neighbour throughout an image and is uncorrelated with homogeneity, contrast and energy. The equation for correlation measurement considers the mean and standard deviation for the rows and columns of the matrix, as shown in Table 2, where $\mu_{x}, \mu_{y}$ and $\sigma_{x}, \sigma_{y}$ represent the mean and standard deviation of probability matrix GLCM along row $\mathrm{x}$ and column $\mathrm{y}$.

Table 2. The Grey-Level Co-Occurrence Matrix (GLCM) features used in this study.

\begin{tabular}{cc}
\hline Method & Formula \\
\hline Homogeneity (HOM) & $\mathrm{HOM}=\sum_{i, j=1}^{N_{g}} \frac{G L C M(i, j)}{1+|i-j|}$ \\
Contrast (CON) & $\mathrm{CON}=\sum_{i, j=1}^{N_{g}}(i-j)^{2} \operatorname{GLCM}(i . j)$ \\
Entropy (ENT) & $\mathrm{ENT}=\sum_{i, j=1}^{N_{g}}(\operatorname{GLCM}(i . j))^{2}$ \\
Correlation (COR) & $\mathrm{COR}=\sum_{i, j=1}^{N_{g}} \frac{\{i \times j\} \times G L C M(i, j)-\left\{\mu_{x} \times \mu_{y}\right\}}{\sigma_{x} \times \sigma_{y}}$ \\
\hline
\end{tabular}

These four textural features were adopted in our analysis, as they have been reported to be effective in discriminating between spatially heterogeneous materials $[33,35]$. We calculated the four textural features using the first and second principal components as opposed to using the eight original spectral bands, for two reasons: first, to reduce the number of the extracted features form thirty two to eight, in order to reduce computational costs; and second, to reduce redundancy while preserving most of the image variability. Finally, the scale of the features (i.e., the size of the sliding window) was also taken into consideration in the experiment section. A sensitivity analysis between classification performance and textural feature scale was carried out.

\subsection{Spectral Differential Features Extraction}

Spectral differential techniques can be adopted to partially eliminate atmospheric effects and the influences of environmental factors (shadows, soil, etc.), which provides a clearer picture of the essential characteristics of the vegetation of concern; these differential data can also be used to extract biochemical information about the vegetation. Some vegetation indices that have been proposed, such as the Yellowness Index (YI), also account for the differential spectral information [36]. This n-degree derivation of the spectrum is essentially the expression of a change related to the status and abundance 
of absorbed biochemical elements, including chlorophyll, water, and nitrogen. The second degree deviation, for example, may be expressed as:

$$
\rho^{\prime \prime}\left(\lambda_{i}\right)=\left[\rho \prime\left(\lambda_{i+1}\right)-\rho \prime\left(\lambda_{i-1}\right)\right] / 2 \Delta \lambda
$$

where $\lambda_{\mathrm{i}}$ is the wavelength at the $i$-th band, $\rho \prime\left(\lambda_{\mathrm{i}}\right)$ is the first-degree deviation of $\lambda_{\mathrm{i}}$, and $\Delta \lambda$ represents the interval between two adjacent bands.

Given the complexity posed by factors such as stray light conditions and uncertain background materials in these ecosystems, differential spectral features may serve to further enhance species identification and composition of mangrove forests. Second-order differentiation spectral feature is adopted in the experiment section.

\subsection{SVM Classifier}

When combining these features, vector stacking is useful when the integrated features are applied to a single classifier. In vector stacking, all of the calculated features, including textural and differential spectral features, are aligned with the original spectral features to form a higher dimensional feature vector for input into the SVM classifier, given its capability and robustness for addressing complex classification problems. As SVM is a fast and efficient machine-learning algorithm and is insensitive to prior distribution assumptions, it can be applied to multi-source data fusion [37]. Therefore, it is reasonable resorting to its ability of dealing with the fused features for mangrove species discrimination.

A flowchart of the methodology adopted in this study is shown in Figure 4.

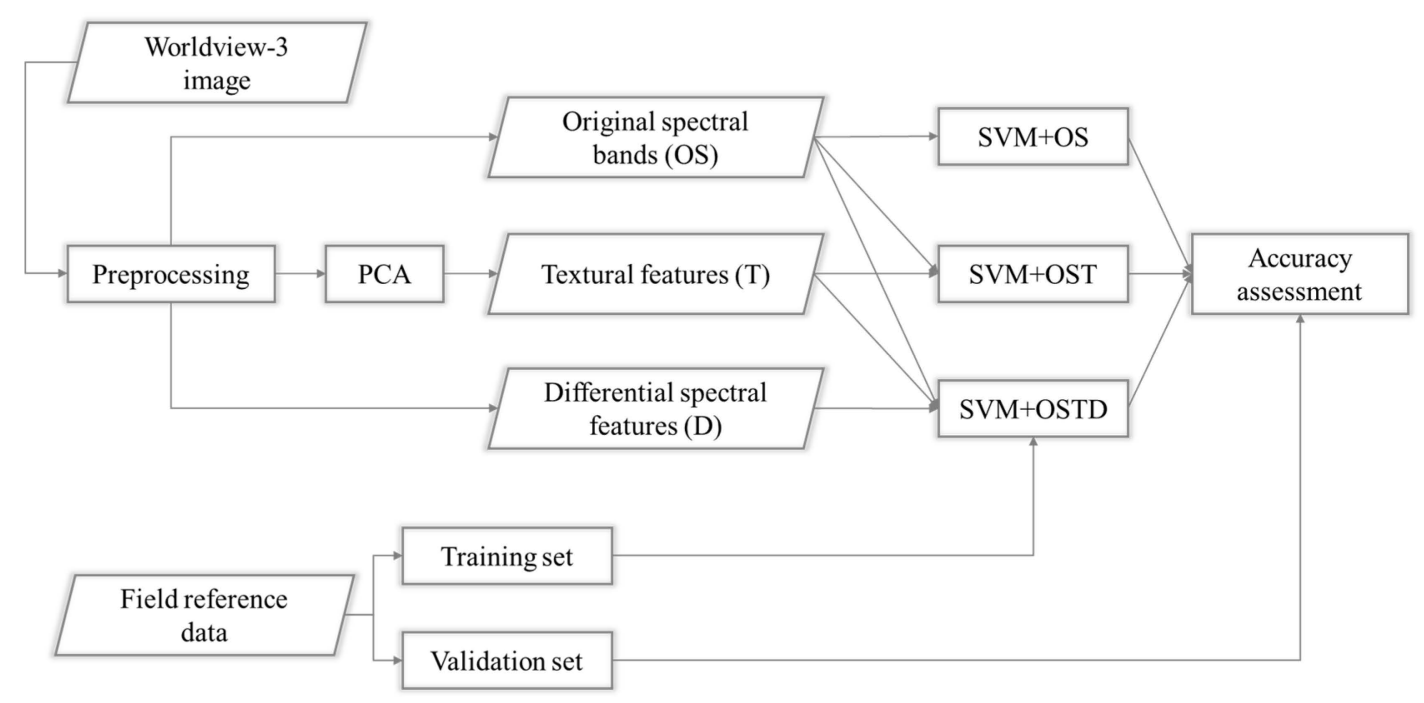

Figure 4. Flowchart of the method used.

\section{Results and Discussion}

We apply the same SVM classifier with three groups of features, respectively. They are: (i) features from Original eight bands Spectral data (OS); (ii) features combining Original Spectra and calculated Textures (OST); and (iii) features combing Original Spectra, calculated Textures and Differential spectral features (OSTD).

For each classifier, cross-validation was used to identify the best model for final classification (see Figure 5). As can be observed, the classification maps of mangrove species are smoother when textural and differential spectral features are included. Considering the density of the mangrove forests in Mai Po, it is thought that smooth maps are more reliable than speckled maps. Moreover, the classification results of the combined features showed an increased agreement with field survey 
data. The overall accuracy of the map was estimated to provide preliminary comparison results (Table 3).

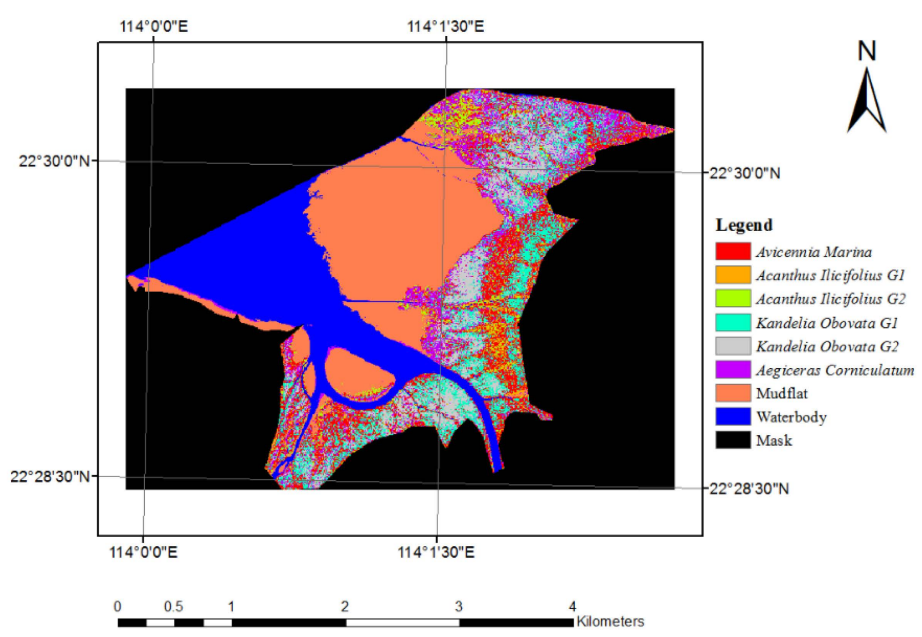

(a)

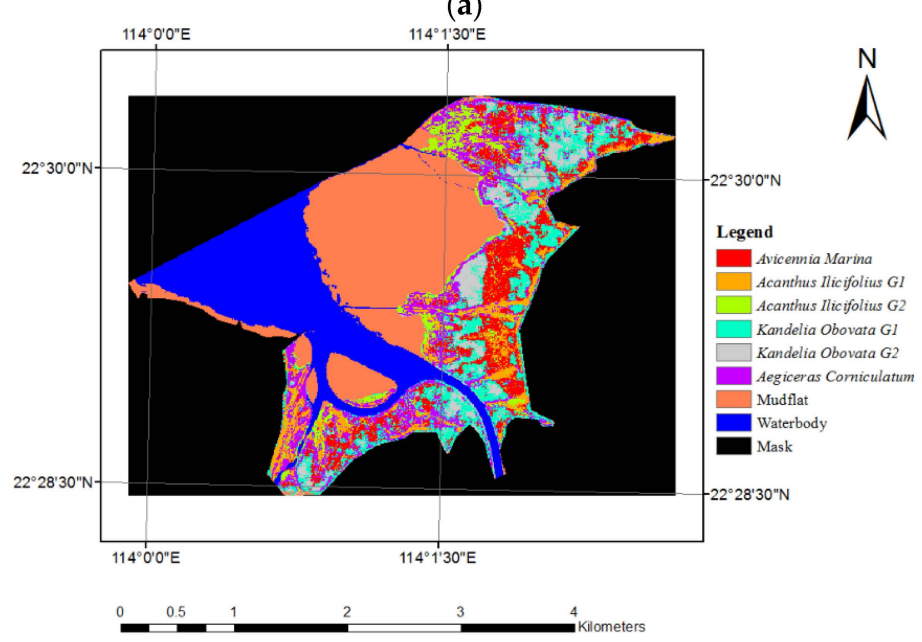

(b)

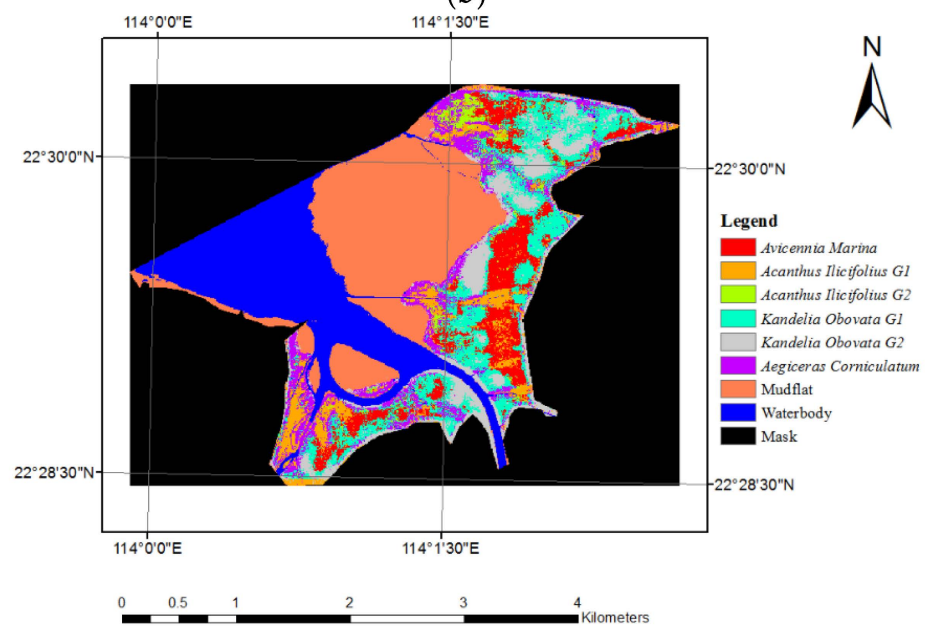

(c)

Figure 5. Classification results of Support Vector Machine (SVM) using different features. (a) SVM + Original Spectra (OS); (b) SVM + Original Spectra and calculated Textures (OST); (c) SVM + Original Spectra, calculated Textures and Differential spectral features (OSTD). 
Table 3. Overall mapping accuracy using the three different sets of features.

\begin{tabular}{cccc}
\hline & SVM + OS & SVM + OST & SVM + OSTD \\
\hline Features Number & 8 & 16 & 23 \\
Test Sample & $83.7838 \%$ & $90.9266 \%$ & $94.4015 \%$ \\
Overall Accuracy & Table 4 & Table 5 & Table 6 \\
Confusion Matrix & \multicolumn{2}{c}{. } \\
\hline
\end{tabular}

The inclusion of textural features improves accuracy of the distribution of mangrove species, which smooths the results and reduces the number of errors from other classes. Here, four types of textural features were adopted, as outlined in Section 3. However, the edge effect caused by the window-based textural features renders the results concerning transitional sections somewhat inaccurate and unreliable.

Classification accuracy can be further enhanced with differential spectral features that are sensitive to essential characteristics of the plant, as noted in Section 3. The second-degree deviation of the spectrum is utilized as the differential spectral feature. Accuracy was assessed base on the validation set of the field collected reference data (Table 3), which shows that incorporating OSTD features into the SVM classifier greatly improves the classification performance of the SVM. For a more detailed analysis, confusion matrices that include both producer and user accuracy were constructed; these are presented in Table 4 for SVM + OS features, Table 5 for SVM + OST features and Table 6 for SVM + OSTD features.

Table 4. Confusion matrix calculated from SVM + OS classification results.

\begin{tabular}{ccccccccccc}
\hline Class & AM & AI1 & AI2 & KO1 & KO2 & AC & Mudflat & Water & Prod. Acc. & User Acc. \\
\hline AM & $\mathbf{7 7 . 4 2}$ & 17.07 & 11.90 & 7.41 & 0.00 & 7.32 & 0.00 & 0.00 & 77.42 & 71.64 \\
AI1 & 3.23 & $\mathbf{1 9 . 5 1}$ & 4.76 & 1.85 & 0.00 & 0.00 & 0.00 & 0.00 & 19.51 & 61.54 \\
AI2 & 9.68 & 56.10 & $\mathbf{7 3 . 8 1}$ & 0.00 & 0.00 & 0.00 & 0.00 & 0.00 & 73.81 & 51.67 \\
KO1 & 4.84 & 0.00 & 2.38 & $\mathbf{7 9 . 6 3}$ & 7.84 & 2.44 & 0.00 & 0.00 & 79.63 & 82.69 \\
KO2 & 0.00 & 0.00 & 2.38 & 11.11 & $\mathbf{8 8 . 2 4}$ & 12.2 & 0.00 & 0.00 & 88.24 & 78.95 \\
AC & 4.84 & 4.88 & 4.76 & 0.00 & 3.92 & $\mathbf{7 8 . 0 5}$ & 0.00 & 0.00 & 78.05 & 78.05 \\
Mudflat & 0.00 & 0.00 & 0.00 & 0.00 & 0.00 & 0.00 & $\mathbf{1 0 0 . 0 0}$ & 0.00 & 100.00 & 100.00 \\
Waterbody & 0.00 & 2.44 & 0.00 & 0.00 & 0.00 & 0.00 & 0.00 & $\mathbf{1 0 0 . 0 0}$ & 100.00 & 98.67 \\
\hline
\end{tabular}

Table 5. Confusion matrix calculated from SVM + OST classification results.

\begin{tabular}{ccccccccccc}
\hline Class & AM & AI1 & AI2 & KO1 & KO2 & AC & Mudflat & Water & Prod. Acc. & User Acc. \\
\hline AM & $\mathbf{8 5 . 4 8}$ & 14.63 & 16.67 & 5.56 & 0.00 & 2.44 & 0.00 & 0.00 & 85.48 & 75.71 \\
AI1 & 1.61 & $\mathbf{6 5 . 8 5}$ & 0.00 & 1.85 & 0.00 & 0.00 & 0.00 & 0.00 & 65.85 & 93.10 \\
AI2 & 4.84 & 17.07 & $\mathbf{7 3 . 8 1}$ & 0.00 & 0.00 & 7.32 & 0.00 & 0.00 & 73.81 & 70.45 \\
KO1 & 3.23 & 0.00 & 2.38 & $\mathbf{8 8 . 8 9}$ & 5.88 & 0.00 & 0.00 & 0.00 & 88.89 & 88.89 \\
KO2 & 3.23 & 0.00 & 0.00 & 1.85 & $\mathbf{9 4 . 1 2}$ & 0.00 & 0.00 & 0.00 & 94.12 & 94.12 \\
AC & 1.61 & 2.44 & 7.14 & 1.85 & 0.00 & $\mathbf{9 0 . 2 4}$ & 0.00 & 0.00 & 90.24 & 86.05 \\
Mudflat & 0.00 & 0.00 & 0.00 & 0.00 & 0.00 & 0.00 & $\mathbf{1 0 0 . 0 0}$ & 0.00 & 100.00 & 100.00 \\
Waterbody & 0.00 & 0.00 & 0.00 & 0.00 & 0.00 & 0.00 & 0.00 & $\mathbf{1 0 0 . 0 0}$ & 100.00 & 100.00 \\
\hline
\end{tabular}


Table 6. Confusion matrix calculated from SVM + OSTD classification results.

\begin{tabular}{ccccccccccc}
\hline Class & AM & AI1 & AI2 & KO1 & KO2 & AC & Mudflat & Water & Prod. Acc. & User Acc. \\
\hline AM & $\mathbf{9 5 . 1 6}$ & 14.63 & 14.29 & 0.00 & 0.00 & 0.00 & 0.00 & 0.00 & 95.16 & 83.10 \\
AI1 & 4.84 & $\mathbf{6 8 . 2 9}$ & 2.38 & 1.85 & 0.00 & 0.00 & 0.00 & 0.00 & 68.29 & 84.85 \\
AI2 & 0.00 & 4.88 & $\mathbf{7 8 . 5 7}$ & 0.00 & 0.00 & 4.88 & 0.00 & 0.00 & 78.57 & 89.19 \\
KO1 & 0.00 & 2.44 & 2.38 & $\mathbf{9 8 . 1 5}$ & 1.96 & 0.00 & 0.00 & 0.00 & 98.15 & 94.64 \\
KO2 & 0.00 & 0.00 & 0.00 & 0.00 & $\mathbf{9 8 . 0 4}$ & 0.00 & 0.00 & 0.00 & 98.04 & 100.00 \\
AC & 0.00 & 7.43 & 2.38 & 0.00 & 0.00 & $\mathbf{9 5 . 1 2}$ & 0.00 & 0.00 & 95.12 & 90.70 \\
Mudflat & 0.00 & 0.00 & 0.00 & 0.00 & 0.00 & 0.00 & $\mathbf{1 0 0 . 0 0}$ & 0.00 & 100.00 & 100.00 \\
Waterbody & 0.00 & 2.44 & 0.00 & 0.00 & 0.00 & 0.00 & 0.00 & $\mathbf{1 0 0 . 0 0}$ & 100.00 & 98.67 \\
\hline
\end{tabular}

Improvements made to both producer and user accuracy are illustrated in Figures 6 and 7. From the tables, it was found that mapping accuracy was enhanced for all six species when textural features are combined, especially with regard to Acanthus ilicifolius Group1, which was inadequately classified using SVM and original spectral features. As can be observed from the AI1 row of Table 4, this species is often confused with AI2 and vice versa, as their spectral features are similar. However, because these two species exhibit different textural features, inclusion of textural features in image analysis greatly improves their classification accuracy, in our case by $45 \%$.

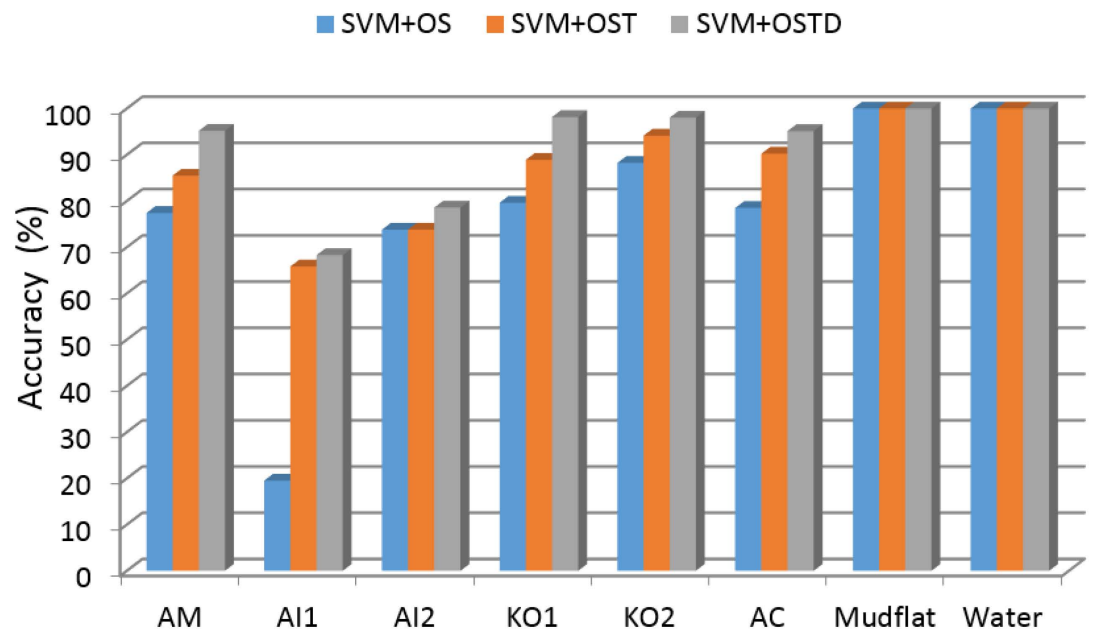

Figure 6. Producer's accuracy.

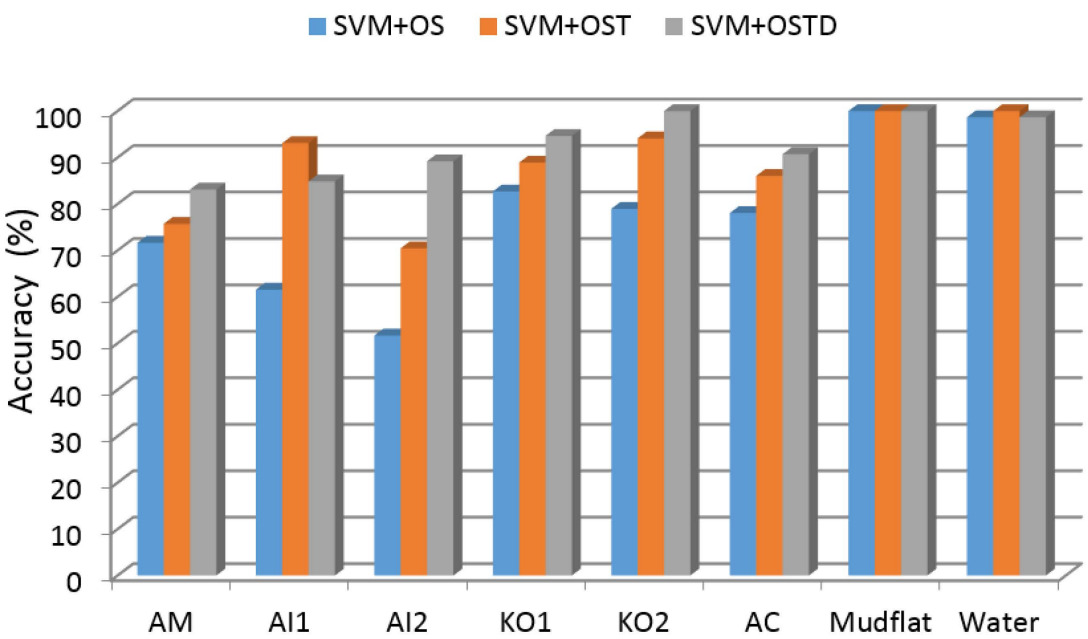

Figure 7. User's accuracy. 
The differential spectral features could further suppress the background interference signals and exploit the intrinsic features of each species. By combining these features, the inter-species differences could be further increased, and intra-species variances could be decreased to some extent, thereby improving classification performance. By optimizing the parameters of the SVM classifier, user's and producer's accuracy had also been greatly improved. Moreover, this approach requires no additional data or parameters, which makes it both a practical and effective method.

We also calculated the area of each species counted by pixels from the classification results in order to make a more comprehensive comparison. The areas are in direct proportion to the pixels and their percentages are shown in Table 7. According to reserve employees, Kandelia obovata is the dominant species of mangrove in Mai Po, which accords with our findings using the SVM + OSTD method.

Table 7. Class area statistics for SVM classifiers with different features.

\begin{tabular}{cccccccc}
\hline Area & AM & AI1 & AI2 & KO1 & KO2 & AC & Overall \\
\hline SVM + OS & $27.3 \%$ & $3.3 \%$ & $7.1 \%$ & $22.3 \%$ & $19.7 \%$ & $20.3 \%$ & $12.25 \mathrm{Ha} \mathrm{(100 \% )}$ \\
SVM + OST & $21.4 \%$ & $11.9 \%$ & $9.7 \%$ & $23.6 \%$ & $11.6 \%$ & $22.6 \%$ & $12.67 \mathrm{Ha}(100 \%)$ \\
SVM + OSTD & $18.8 \%$ & $11.5 \%$ & $4.4 \%$ & $28.2 \%$ & $19.2 \%$ & $17.9 \%$ & $12.57 \mathrm{Ha}(100 \%)$ \\
\hline
\end{tabular}

Determining the optimal window size of textural features is important, as an undersized window will fail to fully exploit the textural arrangement of the objects of interest, whereas an oversized window will result in blurring of the object boundaries [38]. For classification tasks, because the scales of different objects of interest are not identical, a referential window size is preferred. We conducted a sensitivity analysis aimed at determining the optimal window size for calculation of the GLCM matrix. From Figure 8 it can be observed that the best classification result attained was $94.4 \%$ based on a window size of $13 \times 13$ pixels.

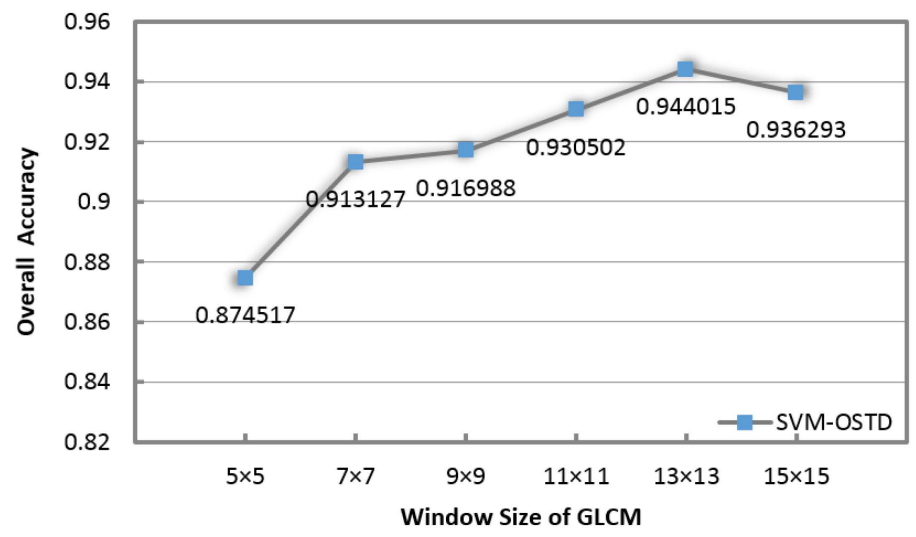

Figure 8. Sensitivity analysis of the spatial scale adopted in the textural features.

When conducting this method, no more data inputs are required besides all the eight multispectral bands of WorldView-3 imagery. There is only one parameter in the feature extraction process: the window size of GLCM, which should be settled according to difference cases. The optimal value of the window size is determined by many factors, such as the scale of the interested object. In the classification process using these integrating features, cross validation could be resorted to as an easy-way to tune the parameters in SVM classifier for best performances. We've reduced the level of difficulty of classification by focusing solely on the mangrove area. However, when the area covers a more complex distribution of landscapes, the effectiveness of the proposed method should be further tested and discussed. 


\section{Conclusions}

We proposed that a feature extraction approach using the latest high-resolution WorldView-3 remotely sensed imagery would be an effective method for discriminating among mangrove species in the mangrove forests of Mai Po Nature Reserve. The textural and differential spectral features further exploit the unique characteristics of the different mangrove species, thereby reducing intra-species variability while increasing inter-species distinction. Incorporating the combined features for the SVM classifier greatly improves mapping accuracy of mangrove species in the Mai Po reserve, an overall accuracy reaching $94.4 \%$, a significant improvement over the $83.7838 \%$ attained focusing solely on the original spectral features from the image. The user accuracy of the main species found in the Mai Po reserve has thus been substantially increased. Similar species, such as the two types of Acanthus ilicifolius, could be distinguished with greater accuracy when their textural and differential spectral features are also considered. This approach has proven to be an efficient and practical method that requires no additional data input or parameters. However, future research should focus on the development of better spatial features tailored to the growth characteristics of the different mangrove species to improve classification performance even further.

Acknowledgments: This work was supported in part by the National Basic Research Program of China (973 Program) under Grant 2015CB954103, Collaborative Innovation Center for Major Security Issues of Jiangxi Province and Monitoring Implementation (No. JXS-EW-00), Direct Grant of the Chinese University of Hong Kong (Project No. 4052093), the National Natural Science Foundation of China (41401370) and the General Research Fund (CUHK 14601515). The authors would like to thank Mingming Jia from Key Laboratory of Wetland Ecology and Environment, Northeast Institute of Geography and Agroecology, Chinese Academy of Sciences for providing the ground truth of the mangrove species distribution in MPMNR. Comments from the editor and three anonymous reviewers are greatly appreciated.

Author Contributions: Ting Wang designed the research, developed the methodology, conducted the experiments and wrote the manuscript draft. Hongsheng Zhang prepared the data and the correspondent training samples, participated in the results interpreting and reviewed the paper. Hui Lin helped with designing the research and reviewed the manuscript. Chaoyang Fang fonded both the research and field work, he also helped with the revising the manuscript. All the authors have read and approved the final manuscript.

Conflicts of Interest: The authors declare no conflict of interest.

\section{References}

1. Food and Agriculture Organization of the United Nations. The World's Mangroves 1980-2005; Food and Agriculture Organization of the United Nations: Rome, Italy, 2007.

2. Szantoi, Z.; Escobedo, F.J.; Abd-Elrahman, A.; Pearlstine, L.; Dewitt, B.; Smith, S. Classifying spatially heterogeneous wetland communities using machine learning algorithms and spectral and textural features. Environ. Monit. Assess. 2015, 187, 1-15. [CrossRef] [PubMed]

3. Suratman, M.N. Carbon sequestration potential of mangroves in southeast Asia. In Managing Forest Ecosystems: The Challenge of Climate Change; Springer: Amsterdam, The Netherlands, 2008; pp. 297-315.

4. Giri, C.; Ochieng, E.; Tieszen, L.L.; Zhu, Z.; Singh, A.; Loveland, T.; Masek, J.; Duke, N. Status and distribution of mangrove forests of the world using earth observation satellite data. Glob. Ecol. Biogeogr. 2011, 20, 154-159. [CrossRef]

5. Szantoi, Z.; Escobedo, F.; Abd-Elrahman, A.; Smith, S.; Pearlstine, L. Analyzing fine-scale wetland composition using high resolution imagery and texture features. Int. J. Appl. Earth Obs. Geoinf. 2013, 23, 204-212. [CrossRef]

6. Green, E.P.; Mumby, P.J.; Edwards, A.J.; Clark, C.D.; Ellis, A.C. The assessment of mangrove areas using high resolution multispectral airborne imagery. J. Coast. Res. 1998, 14, 433-443.

7. Chauvaud, S.; Bouchon, C.; Maniere, R. Remote sensing techniques adapted to high resolution mapping of tropical coastal marine ecosystems (coral reefs, seagrass beds and mangrove). Int. J. Remote Sens. 1998, 19, 3625-3639. [CrossRef]

8. Jia, M.; Zhang, Y.; Wang, Z.; Song, K.; Ren, C. Mapping the distribution of mangrove species in the core zone of Mai Po Marshes nature reserve, Hong Kong, using hyperspectral data and high-resolution data. Int. J. Appl. Earth Obs. Geoinf. 2014, 33, 226-231. [CrossRef] 
9. Kruse, F.A.; Perry, S.L. Mineral mapping using simulated Worldview-3 short-wave-infrared imagery. Remote Sens. 2013, 5, 2688-2703. [CrossRef]

10. Ozesmi, S.L.; Bauer, M.E. Satellite remote sensing of wetlands. Wetl. Ecol. Manag. 2002, 10, $381-402$. [CrossRef]

11. Green, E.P.; Clark, C.D.; Edwards, A.J. Image classification and habitat mapping. In Remote Sensing Handbook for Tropical Coastal Management; UNESCO: Paris, France, 2000; pp. 141-154.

12. Schmidt, K.S.; Skidmore, A.K. Spectral discrimination of vegetation types in a coastal wetland. Remote Sens. Environ. 2003, 85, 92-108. [CrossRef]

13. Heenkenda, M.K.; Joyce, K.E.; Maier, S.W.; Bartolo, R. Mangrove species identification: Comparing Worldview-2 with aerial photographs. Remote Sens. 2014, 6, 6064-6088. [CrossRef]

14. Kuenzer, C.; Bluemel, A.; Gebhardt, S.; Quoc, T.V.; Dech, S. Remote sensing of mangrove ecosystems: A review. Remote Sens. 2011, 3, 878-928. [CrossRef]

15. Wang, L.; Sousa, W.P.; Gong, P.; Biging, G.S. Comparison of IKONOS and Quickbird images for mapping mangrove species on the Caribbean coast of Panama. Remote Sens. Environ. 2004, 91, 432-440. [CrossRef]

16. Everitt, J.H.; Yang, C.; Sriharan, S.; Judd, F.W. Using high resolution satellite imagery to map black mangrove on the Texas Gulf Coast. J. Coast. Res. 2008, 6, 1582-1586. [CrossRef]

17. Heumann, B.W. Satellite remote sensing of mangrove forests: Recent advances and future opportunities. Prog. Phys. Geogr. 2011, 35, 87-108. [CrossRef]

18. Kamal, M.; Phinn, S.; Johansen, K. Object-based approach for multi-scale mangrove composition mapping using multi-resolution image datasets. Remote Sens. 2015, 7, 4753-4783. [CrossRef]

19. Adam, E.; Mutanga, O.; Rugege, D. Multispectral and hyperspectral remote sensing for identification and mapping of wetland vegetation: A review. Wetl. Ecol. Manag. 2010, 18, 281-296. [CrossRef]

20. Vaiphasa, C.; Ongsomwang, S.; Vaiphasa, T.; Skidmore, A.K. Tropical mangrove species discrimination using hyperspectral data: A laboratory study. Estuar. Coast. Shelf Sci. 2005, 65, 371-379. [CrossRef]

21. Wong, F.K.K.; Fung, T. Combining EO-1 hyperion and ENVISAT ASAR data for mangrove species classification in Mai Po Ramsar Site, Hong Kong. Int. J. Remote Sens. 2014, 35, 7828-7856. [CrossRef]

22. Agriculture, Fisheries and Conservation Department. Mai Po Inner Deep Bay Ramsar Site Management Plan Executive Summary; Agriculture, Fisheries and Conservation Department (AFCD): Hong Kong, China, 2011.

23. Rao, C.N.; Sastry, S.S.; Mallika, K.; Tiong, H.S.; Mahalakshmi, K.B. Co-occurrence matrix and its statistical features as an approach for identification of phase transitions of mesogens. Int. J. Innov. Res. Sci. Eng. Technol. 2013, 2, 4531-4538.

24. Huang, X.; Zhang, L.; Wang, L. Evaluation of morphological texture features for mangrove forest mapping and species discrimination using multispectral IKONOS imagery. IEEE Geosci. Remote Sens. Lett. 2009, 6, 393-397. [CrossRef]

25. Demetriades-Shah, T.H.; Steven, M.D.; Clark, J.A. High resolution derivative spectra in remote sensing. Remote Sens. Environ. 1990, 33, 55-64. [CrossRef]

26. Jensen, J.R. Introductory Digital Image Processing: A Remote Sensing Perspective; Pearson Education: Upper Saddle River, NJ, USA, 2005.

27. Talsky, G. Derivative Spectrophotometry: Low and Higher Order; Wiley-VCH: New York, NY, USA, 1994.

28. O'Haver, T.C.; Fell, A.F.; Smith, G.; Gans, P.; Sneddon, J.; Bezur, L.; Michel, R.G.; Ottaway, J.M.; Miller, J.N.; Ahmad, T.A.; et al. Derivative spectroscopy and its applications in analysis. Anal. Proc. 1982, 19, $22-46$. [CrossRef]

29. Tam, N.F.Y.; Wong, Y.-S. Hong Kong Mangroves; City University of Hong Kong Press: Hong Kong, China, 2000.

30. Che, R.G.O. Concentration of 7 heavy metals in sediments and mangrove root samples from Mai Po, Hong Kong. Mar. Pollut. Bull. 1999, 39, 269-279.

31. AFCD. Mangroves in Hong Kong. Available online: http://www.afcd.gov.hk/english/conservation/con _wet/con_wet_man/con_wet_man_local/con_wet_man_local_true.html (accessed on 28 July 2015).

32. Marceau, D.J.; Howarth, P.J.; Dubois, J.-M.M.; Gratton, D.J. Evaluation of the grey-level co-occurrence matrix method for land-cover classification using SPOT imagery. IEEE Trans. Geosci. Remote Sens. 1990, 28, 513-519. [CrossRef]

33. Huang, X.; Liu, X.; Zhang, L. A multichannel gray level co-occurrence matrix for multi/hyperspectral image texture representation. Remote Sens. 2014, 6, 8424-8445. [CrossRef] 
34. Haralick, R.M.; Shanmugam, K.; Dinstein, I.H. Textural features for image classification. IEEE Trans. Syst. Man Cybern. 1973, 6, 610-621. [CrossRef]

35. Ouma, Y.O.; Tetuko, J.; Tateishi, R. Analysis of co-occurrence and discrete wavelet transform textures for differentiation of forest and non-forest vegetation in very-high-resolution optical-sensor imagery. Int. J. Remote Sens. 2008, 29, 3417-3456. [CrossRef]

36. Adams, M.L.; Philpot, W.D.; Norvell, W.A. Yellowness index: An application of spectral second derivatives to estimate chlorosis of leaves in stressed vegetation. Int. J. Remote Sens. 1999, 20, 3663-3675. [CrossRef]

37. Waske, B.; Benediktsson, J.A. Fusion of support vector machines for classification of multisensor data. IEEE Trans. Geosci. Remote Sens. 2007, 45, 3858-3866. [CrossRef]

38. Clausi, D.A. An analysis of co-occurrence texture statistics as a function of grey level quantization. Can. J. Remote Sens. 2002, 28, 45-62. [CrossRef]

(C) 2015 by the authors; licensee MDPI, Basel, Switzerland. This article is an open access article distributed under the terms and conditions of the Creative Commons by Attribution (CC-BY) license (http://creativecommons.org/licenses/by/4.0/). 